\title{
Testosterone and vascular function in aging
}

\author{
Rhéure A. M. Lopes*, Karla B. Neves, Fernando S. Carneiro and Rita C. Tostes*
}

Department of Pharmacology, Medical School of Ribeirao Preto, Ribeirao Preto, São Paulo, Brazil

\section{Edited by:}

Ana Paula Dantas, Institut

d'Investigacions Biomediques August

Pi i Sunyer, Spain

\section{Reviewed by:}

Raghvendra K. Dubey, University Hospital Zurich, Switzerland

Juan Duarte, University of Granada,

Spain

*Correspondence:

Rhéure A. M. Lopes and Rita C. Tostes, Department of

Pharmacology, Medical School of Ribeirao Preto, University of Sao

Paulo, Av Bandeirantes 3900, Ribeirao

Preto, São Paulo 14049-900, Brazil.

e-mail: rheurealves@usp.br;

rtostes@usp.br
Androgen receptors are widely distributed in several tissues, including vascular endothelial and smooth muscle cells. Through classic cytosolic androgen receptors or membrane receptors, testosterone induces genomic and non-genomic effects, respectively. Testosterone interferes with the vascular function by increasing the production of proinflammatory cytokines and arterial thickness. Experimental evidence indicates that sex steroid hormones, such as testosterone modulate the synthesis and bioavailability of NO and, consequently, endothelial function, which is key for a healthy vasculature. Of interest, aging itself is accompanied by endothelial and vascular smooth muscle dysfunction. Aging-associated decline of testosterone levels is accompanied by age-related diseases, such as metabolic and cardiovascular diseases, indicating that very low levels of androgens may contribute to cardiovascular dysfunction observed in these age-related disorders or, in other words, that testosterone may have beneficial effects in the cardiovascular system. However, testosterone seems to play a negative role in the severity of renal disease. In this mini-review, we briefly comment on the interplay between aging and testosterone levels, the vascular actions of testosterone and its implications for vascular aging. Renal effects of testosterone and the use of testosterone to prevent vascular dysfunction in elderly are also addressed.

\section{Keywords: testosterone, aging, vascular function, cardiovascular disease}

\section{INTRODUCTION}

Sex hormones, including testosterone, have important extragonadal effects and experimental and clinical data point to important effects of sex hormones on the cardiovascular system (Reckelhoff, 2005). There is intense debate on the role of testosterone on cardiovascular function and cardiovascular disease (CVD). Whereas high doses of testosterone have been associated with sudden cardiac death and liver disease (Bagatell and Bremner, 1996), low levels are associated with the progression of atherosclerosis, production of pro-inflammatory cytokines, increased arterial thickness, increased levels of glucose, total cholesterol, and low-density lipoprotein, all important in CVD (Hak et al., 2002; Miller et al., 2004; Francomano et al., 2010).

Although reduced testosterone levels in aging men are intimately associated with several aspects of vascular injury, the male $\operatorname{sex}^{1,2}$ is extensively mentioned as a risk factor for CVD, with males having an earlier and higher prevalence of many

\footnotetext{
${ }^{1}$ According to the Department of Reproductive Health and Research, World Health Organization (WHO), http://www.who.int/gender/whatisgender/en/), "Sex" refers to the biological and physiological characteristics that define men and women; "Gender" refers to the socially constructed roles, behaviors, activities, and attributes that a given society considers appropriate for men and women."

${ }^{2}$ As recently reviewed by Miller et al. (2011): "Sex," a biological construct, refers to biological differences defined by sex chromosomes (XX, XY) and the presence of functional reproductive organs and sex steroids. "Gender," a cultural construct, refers to behaviors thought to be directed by specific stimuli or by psychosocial expectations that result or accrue on the basis of assigned or perceived sex. Whereas sex is considered a dichotomous variable; gender is a continuous variable as defined by a range of characteristics that might vary with age, species (animals), or ethnicity (humans), geographical location, education, and culture. Most studies using
}

cardiovascular and metabolic-related diseases (Yang and Reckelhoff, 2011).

In this mini-review, we will briefly comment on the interplay between aging and testosterone levels, the vascular actions of testosterone and its implications for vascular aging. Renal effects of testosterone and the use of testosterone to prevent vascular dysfunction in elderly are also addressed.

\section{BRIEF BIOCHEMISTRY OF TESTOSTERONE SYNTHESIS AND SIGNALING}

More than $95 \%$ of testosterone, the principal male steroid hormone from the androgens group, is produced by the testes and secreted by the Leydig cells, after a series of enzymatic reactions in the cholesterol molecule. Small amounts of testosterone are also secreted by the zona reticularis of the adrenal glands (Sa et al., 2009). In men, normal levels of testosterone range from 10 to $30 \mathrm{nM}$, while much lower levels are found in women (0.6-2.5 nM; Burger, 2002). Testosterone plays a major role in the development of male reproductive tissues and is found in mammals, reptiles, birds, and other vertebrates. In men, testosterone also promotes secondary sexual characteristics, such as increased muscle, bone mass, and the growth of body hair (Mooradian et al., 1987). Although adult human males produce about 10 times more testosterone than the female counterparts, females are very sensitive to the hormone. In women testosterone is synthesized by the theca cells of the ovaries, by

animals categorized by anatomical features and chromosomes can be described as studies of "sex" differences. 
the placenta, as well as by the adrenal cortex (Bassil et al., 2009).

In men, whereas around $7 \%$ of testosterone is reduced to $5 \alpha$-dihydrotestosterone (DHT) by the cytochrome P450 enzyme $5 \alpha$-reductase (an enzyme highly expressed in male accessory sex organs and hair follicles), small amounts (around $0.5 \%$ ) are converted into estradiol by aromatase (CYP19A1, an enzyme expressed in the brain, liver, adipose, and cardiovascular tissues). DHT is more biologically active than testosterone since it binds to the androgen receptor with a 15-fold higher affinity than testosterone (Thigpen et al., 1993; Randall, 1994; Meinhardt and Mullis, 2002; Askew et al., 2007).

Androgen receptors are widely distributed in several cells/tissues, including vascular smooth muscle cells and endothelial cells (Negro-Vilar, 1999). Through classic cytosolic androgen receptors or membrane receptors, testosterone induces genomic and non-genomic effects, respectively. The classical effects of testosterone depends on its binding to the androgen receptor, which acts as a transcription factor that upon association to the androgen response element, modulates transcription, and protein synthesis. The non-genomic effects are rapidly produced, do not require the association of androgen receptors to DNA and therefore are insensitive to the inhibition of RNA and protein synthesis, and involve the activation of various signaling pathways, including calcium-, protein kinase A-, protein kinase C-, and mitogen-activated protein kinase (MAPK)-activated pathways (Bhasin and Jasuja, 2009). It is important to mention that activation of androgen receptors may vary considering whether naturally produced or commercially available hormones are being used, as well as whether metabolic products of androgens are being generated (e.g., testosterone, but not DHT, can be aromatized to $17 \beta$-estradiol) or whether androgen effects were tested on tissues/cells derived from male or female animals (Elbaradie et al., 2011; Toufexis and Wilson, 2012).

\section{EVIDENCE FOR A ROLE OF TESTOSTERONE IN REGULATION OF LONGEVITY}

While the decrease in estrogen and progesterone occurs abruptly in women, testosterone levels decline in men starts in the early years of adulthood, with a $1-2 \%$ reduction per year, and persists throughout life (Harman et al., 2001; Araujo and Wittert, 2011). This reduction is often associated with CVD, metabolic syndrome, insulin resistance, and atherosclerosis. The increased longevity has also been accompanied by an increase in the number of men with hypogonadism (Bassil et al., 2009). Commonly, testosterone replacement improves cardiovascular and metabolic functions (Ruige et al., 2011; Hyde et al., 2012). In addition, a prospective observational study with men aged 70-96 years demonstrated that low testosterone in men, independent of pre-existing health conditions, and other risk factors, is associated with increased mortality risk (Fukai et al., 2011).

Decreased expression of cardiac $\beta 1$-adrenergic receptors is involved in many models of decompensate hypertrophy and heart failure (Bisognano et al., 2000). A study conducted in male Sprague-Dawley rats showed that low levels of testosterone reduced $\beta 1$-adrenoceptor mRNA, while testosterone replacement produced a fourfold increase in $\beta 1$-adrenoceptor mRNA levels.
Testosterone replacement also increased mRNA levels of androgen receptor, $\mathrm{Na}^{+} / \mathrm{Ca}^{2+}$ exchanger, and L-type calcium channel as well as heart weight (Golden et al., 2002). Therefore it is possible that aging-associated testosterone deficiency may contribute to cardiovascular dysfunction in the elderly.

Although many studies indicate that low levels of testosterone represent a risk factor for CVD, men have a higher prevalence of CVD than women and this ratio narrows after menopause (Lerner and Kannel, 1986). In general, explanations for the sex differences in CVD point to a deleterious effect of testosterone or the absence of the cardioprotective effects of estrogen in men (Wu and von Eckardstein, 2003). As elegantly reviewed by Wu and von Eckardstein (2003), a global evaluation of the relationship between androgens and coronary heart disease (CAD) revealed that the data are contradictory, and that is not yet possible to say whether there is a direct association between levels of testosterone or other androgens and CAD. In addition, although testosterone levels in men are positively related to HDL and negatively to LDL, in women this ratio is negative, suggesting that males and females respond differently to androgens, and that some of the beneficial effects of testosterone in men, may be deleterious in women.

Aging-associated CVDs are accompanied by structural and functional changes in the heart and blood vessels. Cardiovascular aging is manifested by maladaptation to stress, cardiac and vascular dysfunction, and heart failure. Aging-associated morphological and functional changes of cardiac and vascular myocytes lead to cardiac and vascular hypertrophy, fibrosis, decreased regenerative capacity of cardiac stem cells/endothelial progenitor cells (EPCs), increased myocyte death due to necrosis and apoptosis (Ungvari et al., 2010; Shih et al., 2011). In the vasculature, increased arterial wall thickening and generalized vascular stiffness are attributed to vascular calcification, increased collagen content/elastin breakdown, and elevated levels of advanced glycation end products (AGEs). In addition, endothelial dysfunction, vascular inflammation, oxidative stress, vascular cell apoptosis also contribute to aging-associated vascular dysfunction, which accelerates CAD, heart failure, stroke, and dementia (Ungvari et al., 2010).

Aging is not only a prominent independent risk factor for CVD, but it is also associated with decreased cognitive function. Of importance, there is strong evidence for a protective role of testosterone in brain regions, including regions susceptible to Alzheimer's disease, such as the hippocampus (Pike et al., 2009). Neuronal damage and apoptosis caused by oxidative stress, a hallmark in aging-associated cardiovascular dysfunction, can also be inhibited by testosterone. Testosterone induces the activation of extracellular-signal-regulated kinases (ERKs), which phosphorylate the pro-apoptotic protein Bad, a member of the pro-apoptotic Bcl-2 family, making it inactive, and increasing neuronal activity. It is known that regions like the hippocampus and cortical regions have a large amount of androgen receptors (Simerly et al., 1990). Interestingly, whereas testosterone inhibits oxidative stress and apoptosis in the brain, our group has shown that testosterone increases reactive oxygen species (ROS) generation (Chignalia et al., 2012) and activates apoptotic pathways (unpublished data) in vascular smooth muscle cells.

Sexual health has also become more important with the increasing longevity in men and women. Erectile dysfunction markedly 
increases with age and men with increased sexual activity have a higher level of bioavailable testosterone than men with erectile dysfunction. Although erectile dysfunction is not a life threatening condition, it directly affects the well-being, self-steam, interpersonal relationship and overall quality of life. It has been suggested that approximately $15-25 \%$ of men over the age of 50 years are expected to have serum testosterone levels that fall below that of the threshold considered normal in men between 20 and 40 years of age (Jockenhovel, 2004). Testosterone improves a great number of androgen deficiency symptoms in the aging male (Giuliano et al., 2004; Amar et al., 2005). Several studies have shown that normal testosterone levels are important for sexual function, and the correlation between hypogonadism and sexual dysfunction is well documented (Shabsigh et al., 2006; Blute et al., 2009; Buvat et al., 2010). For example, testosterone is important for normal erectile function because it regulates nitric oxide (NO), phosphodiesterase-5 (PDE5) levels, and it maintains penile muscle cells (Blute et al., 2009). However, it is important to point out that the main effects of testosterone are not to maintain an erection per se. Conversely, testosterone is much more important for the global aspects of sexual function including libido, orgasm, ejaculatory volume, preserving the general function of the cavernosum and the vasculature involved in the erectile process (Lazarou and Morgentaler, 2005). Accordingly, clinical trials have demonstrated that replacement of testosterone levels in hypogonadal men improves overall sexual function and restores vascular damage in the cavernosal tissue (Seftel et al., 2004; Bassil et al., 2009; Romanelli et al., 2010). In addition, testosterone is essential for health and well-being (Bassil et al., 2009) as well as the prevention of osteoporosis (Tuck and Francis, 2009).

\section{TESTOSTERONE SIGNALING IN VASCULAR AGING}

Experimental data demonstrate that testosterone induces relaxation of many vascular beds, including coronary, mesenteric, iliac, renal, and femoral arteries in several animal species such as rabbit, dog, rat, pig, both in vivo and in vitro conditions. In general, most studies indicate that the relaxation induced by testosterone involves endothelium-independent mechanisms, potassium channel-opening actions and calcium antagonistic effects (Yue et al., 1995; Chou et al., 1996; Crews and Khalil, 1999; Murphy and Khalil, 1999; English et al., 2000, 2002; Deenadayalu et al., 2001).

However, testosterone, as well as other sex steroid hormones (e.g., estrogen) also modulate NO release and, consequently, influence endothelial function (Miller and Mulvagh, 2007). Physiological concentrations of testosterone (and DHT) have been shown to increase endothelial synthesis of $\mathrm{NO}$ via activation of the extracellular-signal-regulated kinase (ERK) $1 / 2$ and phosphatidylinositol 3-OH kinase (PI3K)/Akt cascades (Goglia et al., 2010). Similarly, in rat aortic strips, testosterone significantly increased NO production, via androgen receptor and calcium influx (Campelo et al., 2012). Using endothelial cell cultures these authors demonstrated that testosterone enhances NO production by directly acting in the endothelial cells via PKC- and MAPKdependent pathways. Testosterone also significantly increased DNA synthesis indicating that androgens may also modulate vascular endothelial cell growth (Campelo et al., 2012). In addition, testosterone, at physiological concentrations and via androgen receptor activation, induces proliferation, migration, and colony formation activity of EPCs (Foresta et al., 2008), indicating that the release of EPCs by bone marrow may be an additional mechanism by which testosterone modulates endothelial function (Foresta et al., 2006).

A criticism to the studies reporting the relaxation effects of testosterone in blood vessels is that generally the effects are observed at supraphysiological doses/concentrations, and when physiological concentrations of testosterone were used, the studies were inconclusive, with some showing positive effects, and others neutral or even deleterious effects of testosterone ( $\mathrm{Wu}$ and von Eckardstein, 2003). Furthermore, since most of the studies on the effects of androgens on NO production have been conducted in co-culture systems, it is necessary to assess the direct impact of testosterone on endothelial cell growth and function.

Sader et al. (2001) observed that although low doses of testosterone per se induce vasodilation (brachial artery flow-mediated dilatation, FMD) in healthy men, estradiol supplementation is associated with enhanced arterial vasodilation. The mechanisms by which testosterone and estrogen induce NO release are intertwined, since through the P450 aromatase, testosterone can be converted to estrogen. An excellent review by Miller and Mulvagh (2007) has addressed the mechanisms by which testosterone and estrogen modulate endothelial cells function and NO release. As summarized in Figure 1, the mechanism of action of testosterone in endothelial cell includes classic steroid receptor activation via modulation of gene transcription (genomic), and also membrane receptor activation coupled to fast intracellular signaling (non-genomic). Activation of both estrogen and androgen receptors modulates endothelial function by mechanisms involving activation of Akt, MAPK, tyrosine kinase, and $\mathrm{G}_{\mathrm{i}} \alpha$, culminating in NO synthase activation and release of NO. The agingassociated decrease in testosterone levels may thus compromise this important pathway in vascular tone control.

English and colleagues, in a study with arteries from young and elderly male Wistar rats demonstrated that despite normal contractile responses to prostaglandin F $2 \alpha$, vessels of elderly animals were less sensitive to the vasodilatory effects of testosterone compared to vessels from young animal. This was accompanied by hypertrophy of vascular myocytes, and greater thickening of the smooth muscle layer, in aged animals (English et al., 2000).

Yildiz et al. (2005) demonstrated that the relaxation induced by testosterone in human internal mammary artery is dependent on large conductance $\mathrm{Ca}^{2+}$-activated $\mathrm{K}^{+}$channels $\left(\mathrm{BK}_{\mathrm{Ca}}\right)$. This channel is key in the regulation of vascular tone and arterial diameter and is target to various vasoconstrictor and vasodilator agents. As shown in Figure 1, aging decreases the expression of $\mathrm{BK}_{\mathrm{Ca}}$ channels in coronary smooth muscle and increases endothelial responses to vasoconstrictor agents, which can contribute to the reduced vasodilator response to testosterone in elderly and also increase the risk of vasospasm, myocardial ischemia, and infarction in these individuals (Marijic et al., 2001).

Ripple et al. (1999) showed that, in androgen-sensitive human prostate cancer ( $\mathrm{LNCaP}$ ), androgens increase mitochondrial dehydrogenase activity, levels of cellular peroxides and hydroxyl radicals and the area fraction of mitochondria per cell. The oxidative stress in $\mathrm{LNCaP}$ was abolished in the presence of rotenone and antimycin 


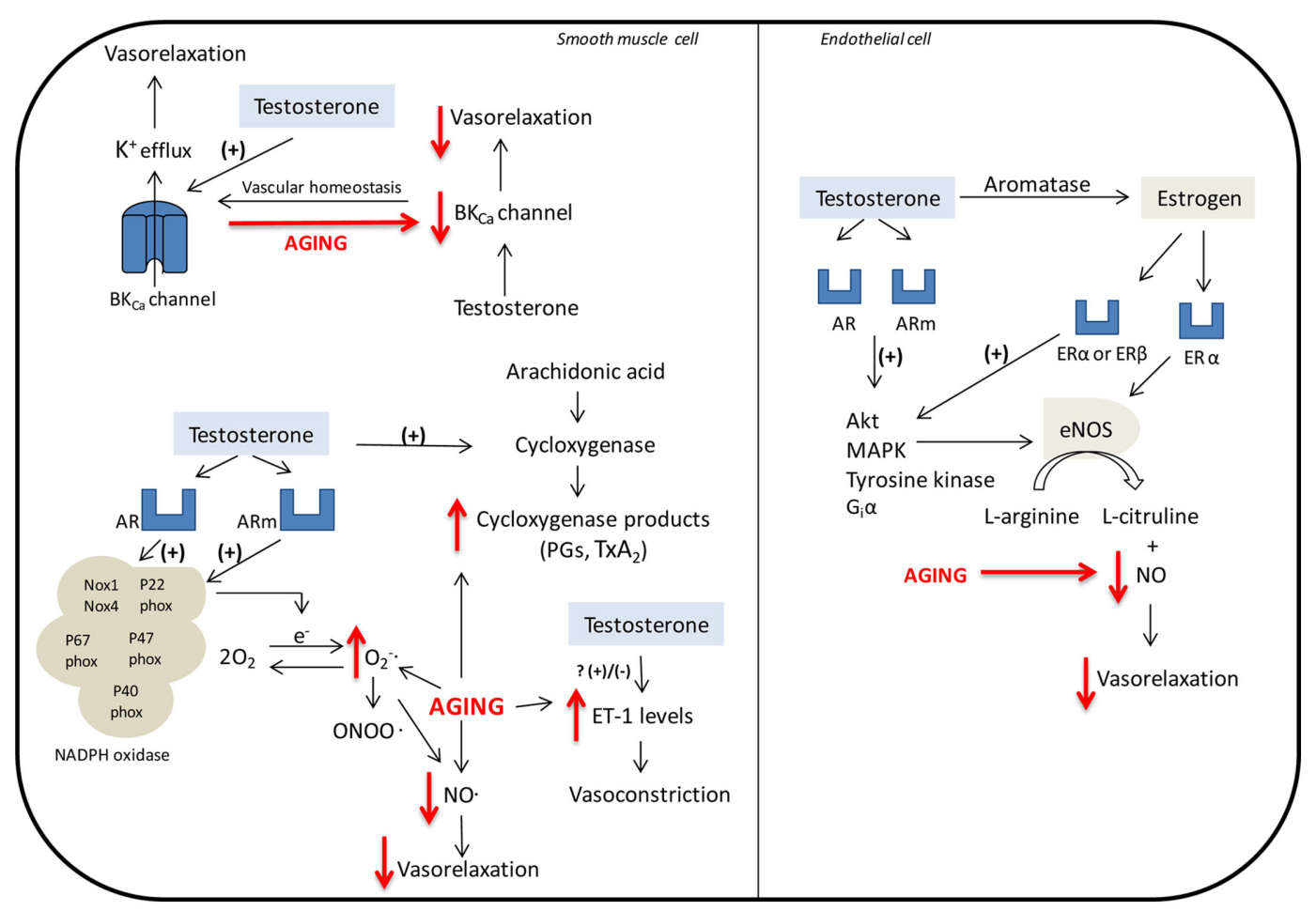

FIGURE 1 | Mechanisms involved in the regulation of vascular function by testosterone. Smooth muscle cell: The relaxation induced by testosterone is dependent on large conductance $\mathrm{Ca}^{2+}$-activated $\mathrm{K}^{+}$channels $\left(\mathrm{BK}_{\mathrm{Ca}}\right)$. Aging decreases the expression of $\mathrm{BK}_{\mathrm{Ca}}$, which can determine the reduced vasodilator response to testosterone in elderly. Testosterone induces NADPH oxidase-dependent $\mathrm{ROS}$ generation. $\mathrm{NO}$ can react with $\bullet \mathrm{O}_{2}^{-}$forming peroxynitrite $\left(\mathrm{ONOO}^{-}\right)$. This decreases $\mathrm{NO}$ availability and consequently reduces vasodilator responses. Testosterone also stimulates COX-1/COX-2 and ET-1 pathways. Endothelial cell: Through the P450 aromatase, testosterone can be converted to estrogen. Activation of estrogen and androgen receptors modulates endothelial function by mechanisms involving release of NO via NO synthase. Abbreviations: AR, androgen receptor; ER estrogen receptor; Akt, serine/threonine kinase; $\mathrm{BK}_{\mathrm{Ca}}$, large conductance $\mathrm{Ca}^{2+}$-activated $\mathrm{K}^{+}$channels; ERKs, extracellular-signal-regulated kinases; eNOS, endothelial NO synthase; $G_{i} \alpha$, guanine nucleotide regulator protein subunit that inhibits guanylate cyclase; MAPK, mitogen-activated protein kinase; $\bullet \mathrm{O}_{2}^{-}$, superoxide anion; $\mathrm{ONOO}^{-}$, peroxynitrite; $\mathrm{PGs}$, prostaglandins; $\mathrm{TxA}_{2}$, thromboxane $\mathrm{A}_{2}$. Aging-associated decline in testosterone levels, as well as mechanisms that contribute to aging-associated endothelial dysfunction are depicted in red.
A (electron transport system inhibitors), and abrogated in the presence of alpha-tocopherol succinate. These data indicate that ROS generation induced by androgen in LNCaP involves mitochondrial pathways and is sensitive to antioxidants. On the other hand, Hwang et al. (2011) demonstrated that treatment of Leydig cells with low doses of testosterone has cytoprotective effects by decreasing ROS and lipid peroxides. However, cytotoxic effects, due to increased ROS generation, were found with high doses of testosterone. Although data from our laboratory demonstrate that testosterone induces ROS generation in VSMCs (Chignalia et al., 2012), which can culminate in decreased NO bioavailability and reduce vasodilator responses, it is not known whether this effect is altered in senescent VSMCs.

Testosterone also stimulates thromboxane synthase as well as COX-1 and COX-2, which are key enzymes in the synthesis of prostaglandins (Cheuk et al., 2000; Song et al., 2004). Accordingly, the aging-associated decrease in testosterone levels may interfere with vascular function via changes in the thromboxane/COX pathway (Figure 1).

de Souza Rossignoli et al. (2010), in a study to determine the effects of declining levels of testosterone, as occurs in aging, and testosterone replacement on vascular function, found that orchidectomy enhanced the maximum responses of the portal vein to phenylephrine. However, testosterone replacement had no effect on these responses. Yet in this study, orchidectomy-induced increased maximum response to phenylephrine was not altered by a NOS inhibitor alone or combined with indomethacin. Interestingly, the increased response was abolished in the presence of ETA and ETB receptor antagonists (BQ-123 and BQ-788, respectively), suggesting that increased contractile responses to phenylephrine induced by decreases in plasma testosterone, involves activation of ETA and ETB receptors. The relationship between testosterone and endothelin-1 (ET-1) is complex. Whereas substantial data support the idea that testosterone positively modulates ET-1 levels and ET1-mediated vasoconstrictor responses, other reports indicate that ET-1 levels are higher in conditions associated with low levels of testosterone, as in hypogonadism (Tostes et al., 2008).

The regulation of resting membrane potential is mostly dependent on the voltage-dependent potassium channels (Kv), and functional changes of these channels may impair vascular function. $\mathrm{Kv}$ plays a key role in endothelial cells function and is decreased in stroke-prone spontaneously hypertensive rats (Sadanaga et al., 
2002). Zhou et al. (2008) investigated the effects of testosterone deprivation (castration -6 months) as well as the effects of testosterone replacement therapy on the function of $\mathrm{Kv}$ channels in rat thoracic aortic VSMCs. In this study long-term deprivation of endogenous testosterone decreased the expression of Kv1.5 protein, which culminated in reduced function of $\mathrm{Kv}$ channels. Testosterone replacement restored the impaired function of $\mathrm{Kv}$, which suggests that testosterone deficiency in aging may impair vascular function via a decrease of endothelial and vascular smooth muscle $\mathrm{Kv}$ channels.

As already mentioned, aging is accompanied by endothelial dysfunction (Yildiz, 2007). There is extensive discussion on the mechanisms by which the aging process attenuates endotheliumdependent dilatation. Enhanced production of endotheliumderived vasoconstrictor prostanoids, decreased NO bioavailability, increased expression/activity of ET-1, and augmented ROS generation are all potential mechanisms involved in aging-associated endothelial injury and vascular dysfunction (Mombouli and Vanhoutte, 1999; Blackwell et al., 2004; Vanhoutte et al., 2009). The generation of superoxide anion $\left(\bullet \mathrm{O}_{2}^{-}\right)$results in rapid formation of hydrogen peroxide $\left(\mathrm{H}_{2} \mathrm{O}_{2}\right)$ via mitochondrial manganese superoxide dismutase (MnSOD). $\mathrm{NO}$ can react with $\bullet \mathrm{O}_{2}^{-}$forming peroxynitrite $\left(\mathrm{ONOO}^{-}\right)$that inactivates $\mathrm{MnSOD}$ and may also uncouple NO synthase. Both reactions decrease the availability of $\mathrm{NO}$ and consequently reduce vasodilator responses (Yildiz, 2007). Decreased NO bioavailability is also associated with endothelial NO synthase (eNOS) dysfunction since uncoupled eNOS is a source of $\bullet \mathrm{O}_{2}^{-}$in the vasculature. Accordingly, removal of endothelial cells, as well as pharmacological inhibition of NOS, reverses the vascular increased $\bullet \mathrm{O}_{2}^{-}$production of aged vessels. In aging, eNOS uncoupling seems to be associated with a reduction of the cofactor tetrahydrobiopterin availability (Delp et al., 2008; Yang et al., 2009) rather than to a deficiency of L-arginine substrate concentration (Gates et al., 2007). In addition, eNOS knockout male mice have a significantly shorter lifespan than their wild type controls and exhibit accelerated aging-dependent cardiac dysfunction. Regarding ET-1 and aging, plasma ET-1 concentrations increase with age (Battistelli et al., 1996; Donato et al., 2009; Goel et al., 2010), ET-1-mediated vasoconstriction is augmented in older adults (Thijssen et al., 2007; Van Guilder et al., 2007) and synthesis of ET-1 is greater in cultured aortic endothelial cells obtained from older donors compared with young ones (Tokunaga et al., 1992). Finally, inhibition of ET-1 signaling with an ETA receptor antagonist improves endothelial dysfunction in arteries from old mice, while not affecting dilation in young controls (Donato et al., 2009). As discussed above, testosterone has been shown to modulate each of these mechanisms that contribute to aging-associated endothelial dysfunction. However, whether decreased testosterone levels are directly associated with the endothelial dysfunction and increased incidence of CVDs remains controversial.

Hypogonadism is a condition associated with endothelial dysfunction (Akishita et al., 2007; Foresta et al., 2008). A study where male patients were submitted to examination of vasomotor function of the brachial artery and intima-media thickness (IMT) of the carotid artery, showed that low levels of testosterone are associated with endothelial dysfunction, independent of age, body mass index, hypertension, hyperlipidemia, diabetes mellitus, or current smoking, suggesting a protective effect of testosterone on endothelial function (Akishita et al., 2007).

\section{THE USE OF TESTOSTERONE TO PREVENT VASCULAR DYSFUNCTION IN ELDERLY}

Testosterone replacement therapy has been shown to decrease total cholesterol, low-density lipoprotein, and triglycerides, to increase high density lipoprotein, and also to inhibit fatty streak formation, indicating that androgens may have protective effects against atherosclerosis (Nettleship et al., 2007, 2009; Saad et al., 2008).

Likewise, testosterone has been shown to improve hemodynamic parameters in patients and animal models of heart failure, especially via a reduction in peripheral vascular resistance and increased coronary blood flow through vasodilation and via direct effects in the cardiac tissue (e.g., by inhibition of cardiac cAMPphosphodiesterases; Bordallo et al., 2011; Nguyen et al., 2011).

Through the measurement of pulse wave velocity, a technique that allows to analyze arterial stiffness (decreased compliance), vascular disease, and also to predict future cardiovascular events (Boutouyrie et al., 2002; Pizzi et al., 2006), Yaron and colleagues reported that pulse wave velocity was significantly higher in men with hypogonadism. Transdermal testosterone replacement therapy increased androgen bioavailability and decreased pulse wave velocity, indicating that testosterone replacement can diminish arterial stiffness associated with male hypogonadism (Yaron et al., 2009).

The decline in testosterone levels observed with aging occurs at a time when prostate diseases start to emerge. Excellent results have been found with new testosterone preparations via different routes of administration (Titus et al., 2005). $5 \alpha$-reductase inhibition (with finasteride), which is used in the treatment of men with benign prostatic hyperplasia (McConnell et al., 1992), also improves the quality of life of these patients.

Decreased levels of dehydroepiandrosterone (DHEA), a precursor of testosterone, are also associated with aging-related diseases. Although its mechanisms of action remain poorly understood, DHEA replacement therapy exerts positive anti-aging, antiobesity, anti-atherosclerosis, anti-diabetic, and anti-osteoporosis effects (Gomez-Santos et al., 2011).

The above-mentioned data indicate that testosterone actions on the vasculature are beneficial and that low levels of testosterone are detrimental to cardiovascular function. Testosterone replacement may be beneficial in the treatment of diseases characteristic of elderly, but the positive cardiovascular benefits resulting from it need to be clearly demonstrated in large clinical trials.

If, in one hand, androgens seem to confer cardioprotection, on the other hand androgens can increase blood pressure and induce renal dysfunction, which may adversely influence the cardiovascular system. For example, chronic infusion of DHT increased sodium and water reabsorption and subsequently blood pressure in Sprague-Dawley rats (Quan et al., 2004). Further support to the idea that testosterone may have deleterious effects on renal function derives from studies in animals with arterial hypertension. Orchidectomy in male SHR prevents aging-associated increase in renal vascular resistance and reduces renal superoxide production (Reckelhoff et al., 2005). In addition, physiological concentrations of DHT increase dihydroethidium fluorescence in cultured 
mesangial cells from SHR (Reckelhoff et al., 2005), whereas tempol, a SOD mimetic, reduces ROS generation and blood pressure in SHR (Fortepiani and Reckelhoff, 2005). Considering that testosterone also induces ROS generation in VSMCs from SHR (Chignalia et al., 2012) and that superoxide, the major ROS found in kidneys, reduces NO bioavailability and increases renal vasoconstriction (Reckelhoff and Romero, 2003; Yildiz, 2007), it is possible that testosterone may directly contribute to renal damage and vascular dysfunction via ROS generation. Furthermore, in the renal wrap model of hypertension, castration of male rats decreases renal damage, and DHT treatment of castrated males, reverses it, suggesting that androgens may directly contribute to the development of renal failure (Ji et al., 2005).

However, studies also suggest a renoprotective role for testosterone. For example, reduced levels of testosterone correlates with the development of albuminuria, a marker of diabetic renal disease, and castration of streptozotocin-treated rats potentiates diabetes-associated albuminuria (Xu et al., 2008). In addition, clinical studies show reduced levels of testosterone in diabetic patients (Laaksonen et al., 2004; Ding et al., 2006; Kapoor et al., 2007), raising the possibility that the severity of renal disease in these patients is partially due to a decrease in testosterone levels. A study conducted in 36 outpatient centers in Belgium, France, Germany, Italy, the Netherlands, Spain, Sweden, and the UK between February 2006 and March 2007 evaluated the effects of testosterone replacement therapy on insulin resistance in hypogonadal men with type 2 diabetes. Testosterone replacement reduced insulin resistance and improved glycemic control in the overall population (Jones et al., 2011). Furthermore, promising results arose from a study in which testosterone replacement was used for 2 years in type 2 diabetic male patients, who had the first ischemic stroke. Several parameters were improved by testosterone replacement on those patients, such as body mass index, glycated hemoglobin, cholesterol, triglycerides, and low-density lipoproteins. Furthermore, only $7.1 \%$ of the patients receiving testosterone replacement had a secondary stroke compared with $16.6 \%$ in the control group (Morgunov et al., 2011). These data indicate that testosterone replacement may be important to reduce cardiovascular risk factors, especially in type 2 diabetes associated with the hypogonadism condition.

It is unknown whether renal dysfunction or renal protection by testosterone is associated with direct effects of testosterone on the renal cells, or indirect effects of the hormone (e.g., in the renal vasculature). Since human renal proximal tubule and cortical collecting duct cells express enzymes involved in androgen synthesis (Quinkler et al., 2003) as well as androgen receptors (Kimura et al., 1993), one may speculate that testosterone regulates renal function by direct mechanisms.

Although data on testosterone and androgens being bad/deleterious or good/beneficial to the cardiovascular and renal systems are still very controversial, in general, experimental evidence indicates that testosterone is essential for the equilibrium in the actions of many endothelium-derived vasoactive agents as well as for the appropriate function of structural components of these systems (Table 1). The aging-associated decrease in testosterone levels may disrupt these signals and therefore contribute to cardiovascular and renal dysfunction observed in elderly.

\section{CONCLUSION AND PERSPECTIVES}

Even though evidence indicates that vascular damage characteristic of aging may be improved or even reversed with testosterone replacement therapy, more studies are needed to confirm the putative beneficial cardiovascular effects of testosterone therapy. In addition, the long-term effects of testosterone replacement therapy need to be carefully addressed. For example, whereas short-term testosterone treatment has been shown to produce a wide range of benefits (it improves hemodynamic parameters, cognitive and sexual function, mood, muscle mass and strength), the beneficial effects may not be maintained (the gain of muscle mass, strength, and quality of life are not maintained at 6 months post-treatment

Table 1 | Cardiovascular and renal effects mediated by androgens.

\begin{tabular}{|c|c|c|c|}
\hline Androgen & Cell/tissue & Effect & Reference \\
\hline Testosterone & Heart & $\begin{array}{l}\uparrow \beta 1 \text {-Adrenoceptor, } \uparrow \text { androgen receptor, } \uparrow \\
\mathrm{Na}^{+} / \mathrm{Ca}^{2+} \text { exchanger, } \uparrow \text { L-type calcium channel }\end{array}$ & Golden et al. (2002) \\
\hline Testosterone & Cultured VSMCs & $\uparrow \operatorname{ROS}$ & Chignalia et al. (2012) \\
\hline $\begin{array}{l}\text { Testosterone/ } \\
\text { dihydrotestosterone }\end{array}$ & Human endothelial cells, blood vessels & $\uparrow \mathrm{ERK} 1 / 2, \uparrow \mathrm{PI} 3 \mathrm{~K}, \uparrow \mathrm{eNOS}, \uparrow \mathrm{NO}$ & $\begin{array}{l}\text { Goglia et al. (2010), Miller } \\
\text { and Mulvagh (2007) }\end{array}$ \\
\hline Testosterone & Brachial artery & $\uparrow \mathrm{FMD}$ & Sader et al. (2001) \\
\hline Testosterone & Human internal mammary artery & $\uparrow \mathrm{BK}_{\mathrm{Ca}}$ activation & Yildiz et al. (2005) \\
\hline Testosterone & $\begin{array}{l}\text { Rat epididymis, thoracic aortae, and } \\
\text { mesenteric arteries }\end{array}$ & $\uparrow \mathrm{COX}-1$ and COX-2 & $\begin{array}{l}\text { Cheuk et al. (2000), Song } \\
\text { et al. (2004) }\end{array}$ \\
\hline Testosterone & Rat thoracic aorta & $\uparrow$ Kv channels & Zhou et al. (2008) \\
\hline Testosterone & Endothelial cells & $\uparrow \mathrm{EPCs}$ & Foresta et al. (2008) \\
\hline Dihydrotestosterone & Kidney & $\uparrow$ Sodium and water reabsorption & Quan et al. (2004) \\
\hline Dihydrotestosterone & Mesangial cells & $\uparrow \operatorname{ROS}$ & Reckelhoff et al. (2005) \\
\hline
\end{tabular}

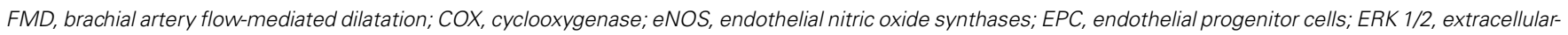

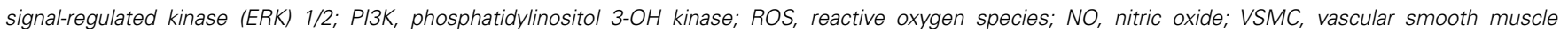
cell. 
with testosterone in frail elderly men; O'Connell et al., 2011). Does the same happen with the cardiovascular effects (are the benefits sustained or not)? What is the optimal duration of anabolic hormonal intervention? Are any possible side effects (e.g., prostatic disease and erythrocytosis) overruled by the beneficial cardiovascular effects? Do physical exercise, diet, and other lifestyle options, in conjunction with pharmacological testosterone replacement, improve beneficial cardiovascular effects of hormone therapy?

\section{REFERENCES}

Akishita, M., Hashimoto, M., Ohike, Y., Ogawa, S., Iijima, K., Eto, M., and Ouchi, Y. (2007). Low testosterone level is an independent determinant of endothelial dysfunction in men. Hypertens. Res. 30, 1029-1034.

Amar, E., Grivel, T., Hamidi, K., Lemaire, A., and Giuliano, F. (2005). Ageing men's sexual functions decline and the erectile dysfunction (ED) increase. Prog. Urol. 15, 6-9.

Araujo, A. B., and Wittert, G. A. (2011). Endocrinology of the aging male. Best Pract. Res. Clin. Endocrinol. Metab. 25, 303-319.

Askew, E. B., Gampe, R. T. Jr., Stanley, T. B., Faggart, J. L., and Wilson, E. M. (2007). Modulation of androgen receptor activation function 2 by testosterone and dihydrotestosterone. J. Biol. Chem. 282, 25801-25816.

Bagatell, C. J., and Bremner, W. J. (1996). Androgens in men - uses and abuses. N. Engl. J. Med. 334, 707-714.

Bassil, N., Alkaade, S., and Morley, J. E. (2009). The benefits and risks of testosterone replacement therapy: a review. Ther. Clin. Risk. Manag. 5, 427-448.

Battistelli, S., Gori, S., Borgogni, T., and Manasse, G. (1996). Variation in the plasma endothelin levels in relation to age. Minerva Cardioangiol. 44, 111-114.

Bhasin, S., and Jasuja, R. (2009). Selective androgen receptor modulators as function promoting therapies. Curr. Opin. Clin. Nutr. Metab. Care 12, 232-240.

Bisognano, J. D., Weinberger, H. D., Bohlmeyer, T. J., Pende, A., Raynolds, M. V., Sastravaha, A., Roden, R., Asano, K., Blaxall, B. C., Wu, S. C., Communal, C., Singh, K., Colucci, W., Bristow, M. R., and Port, D. J. (2000). Myocardial-directed overexpression of the human beta(1)adrenergic receptor in transgenic mice. J. Mol. Cell. Cardiol. 32, 817-830.

Blackwell, K. A., Sorenson, J. P., Richardson, D. M., Smith, L. A., Suda, O., Nath, K., and Katusic, Z. S. (2004). Mechanisms of aging-induced impairment of endothelium-dependent relaxation: role of tetrahydrobiopterin. Am. J. Physiol. Heart Circ. Physiol. 287, H2448-H2453.

Blute, M., Hakimian, P., Kashanian, J., Shteynshluyger, A., Lee, M., and Shabsigh, R. (2009). Erectile dysfunction and testosterone deficiency. Front. Horm. Res. 37, 108-122.

Bordallo, J., Cantabrana, B., Suarez, L., and Sanchez, M. (2011). Testosterone inhibits cAMPphosphodiesterases in heart extracts from rats and increases cAMP levels in isolated left atria. Pharmacology 87, 155-160.

Boutouyrie, P., Tropeano, A. I., Asmar, R., Gautier, I., Benetos, A., Lacolley, P., and Laurent, S. (2002). Aortic stiffness is an independent predictor of primary coronary events in hypertensive patients: a longitudinal study. Hypertension 39, 10-15.

Burger, H. G. (2002). Androgen production in women. Fertil. Steril. 77(Suppl. 4), S3-S5.

Buvat, J., Maggi, M., Gooren, L., Guay, A. T., Kaufman, J., Morgentaler, A., Schulman, C., Tan, H. M., Torres, L. O., Yassin, A., and Zitzmann, M. (2010). Endocrine aspects of male sexual dysfunctions. J. Sex. Med. 7(Pt 2), 1627-1656.

Campelo, A. E., Cutini, P. H., and Massheimer, V. L. (2012). Testosterone modulates platelet aggregation and endothelial cell growth through nitric oxide pathway. $J$. Endocrinol. 213, 77-87.

Cheuk, B. L., Leung, P. S., Lo, A. C., and Wong, P. Y. (2000). Androgen control of cyclooxygenase expression in the rat epididymis. Biol. Reprod. 63, 775-780.

Chignalia, A. Z., Schuldt, E., Camargo, L., Montezano, A. C. I., Callera, G. E., Laurindo, F. R., Lopes, L. R., Avellar, M. C. W., Carvalho, M. H. C., Fortes, Z. B., Touyz, R. M., and Tostes, R. C. (2012). Testosterone induces vascular smooth muscle cell migration by NADPH oxidase and c-SRCdependent pathways. Hypertension (in press).

Chou, T. M., Sudhir, K., Hutchison, S. J., Ko, E., Amidon, T. M., Collins, P., and Chatterjee, K. (1996). Testosterone

These questions clearly illustrate that the cardiovascular benefits of testosterone therapy for age-related declines are not yet as clear as they may seem.

\section{ACKNOWLEDGMENTS}

FAPESP (Fundaçao de Amparo a Pesquisa do Estado de Sao Paulo) and $\mathrm{CNPq}$ (Conselho Nacional de Desenvolvimento Cientifico e Tecnologico), Brazil.

induces dilation of canine coronary conductance and resistance arteries in vivo. Circulation 94, 2614-2619.

Crews, J. K., and Khalil, R. A. (1999). Antagonistic effects of 17 betaestradiol, progesterone, and testosterone on $\mathrm{Ca}^{2+}$ entry mechanisms of coronary vasoconstriction. Arterioscler. Thromb. Vasc. Biol. 19, 1034-1040.

de Souza Rossignoli, P., Pereira, O. C., and Chies, A. B. (2010). Orchidectomy enhances the effects of phenylephrine in rat isolated portal vein. Clin. Exp. Pharmacol. Physiol. 37, 368-374.

Deenadayalu, V. P., White, R. E., Stallone, J. N., Gao, X., and Garcia, A. J. (2001). Testosterone relaxes coronary arteries by opening the large-conductance, calciumactivated potassium channel. Am. J. Physiol. Heart Circ. Physiol. 281, H1720-H1727.

Delp, M. D., Behnke, B. J., Spier, S. A., Wu, G., and Muller-Delp, J. M. (2008). Ageing diminishes endothelium-dependent vasodilatation and tetrahydrobiopterin content in rat skeletal muscle arterioles. J. Physiol. (Lond.) 586, 1161-1168.

Ding, E. L., Song, Y., Malik, V. S., and Liu, S. (2006). Sex differences of endogenous sex hormones and risk of type 2 diabetes: a systematic review and meta-analysis. JAMA 295, 1288-1299.

Donato, A. J., Gano, L. B., Eskurza, I., Silver, A. E., Gates, P. E., Jablonski, K., and Seals, D. R. (2009). Vascular endothelial dysfunction with aging: endothelin-1 and endothelial nitric oxide synthase. Am. J. Physiol. Heart Circ. Physiol. 297, H425-H432.

Elbaradie, K., Wang, Y., Boyan, B. D. and Schwartz, Z. (2011). Rapid membrane responses to dihydrotestosterone are sex dependent in growth plate chondrocytes. J. Steroid Biochem. Mol. Biol. doi: 10.1016/j.jsbmb.2011.12.009. [Epub ahead of print].

English, K. M., Jones, R. D., Jones, T. H., Morice, A. H., and Channer, K. S. (2000). Aging reduces the responsiveness of coronary arteries from male Wistar rats to the vasodilatory action of testosterone. Clin. Sci. 99, 77-82.

English, K. M., Jones, R. D., Jones, T. H., Morice, A. H., and Channer, K. S. (2002). Testosterone acts as a coronary vasodilator by a calcium antagonistic action. J. Endocrinol. Invest. 25, 455-458.

Foresta, C., Caretta, N., Lana, A., De Toni, L., Biagioli, A., Ferlin, A., and Garolla, A. (2006). Reduced number of circulating endothelial progenitor cells in hypogonadal men. J. Clin. Endocrinol. Metab. 91, 4599-4602.

Foresta, C., Zuccarello, D., De Toni, L., Garolla, A., Caretta, N., and Ferlin, A. (2008). Androgens stimulate endothelial progenitor cells through an androgen receptormediated pathway. Clin. Endocrinol. (Oxf.) 68, 284-289.

Fortepiani, L. A., and Reckelhoff, J. F. (2005). Role of oxidative stress in the sex differences in blood pressure in spontaneously hypertensive rats. J. Hypertens. 23, 801-805.

Francomano, D., Bruzziches, R., Natali, M., Aversa, A., and Spera, G. (2010). Cardiovascular effect of testosterone replacement therapy in aging male. Acta Biomed. 81(Suppl. 1), 101-106.

Fukai, S., Akishita, M., Yamada, S., Ogawa, S., Yamaguchi, K., Kozaki, K., Toba, K., and Ouchi, Y. (2011). Plasma sex hormone levels and mortality in disabled older men and women. Geriatr. Gerontol. Int. 11, 196-203.

Gates, P. E., Boucher, M. L., Silver, A. E., Monahan, K. D., and Seals, D. R. (2007). Impaired flowmediated dilation with age is not explained by L-arginine bioavailability or endothelial asymmetric dimethylarginine protein expression. J. Appl. Physiol. 102, 63-71.

Giuliano, F., Tostain, J., and Rossi, D. (2004). Testosterone and male sexuality: basic research and clinical data. Prog. Urol. 14, 783-790.

Goel, A., Su, B., Flavahan, S., Lowenstein, C. J., Berkowitz, D. E., and Flavahan, N. A. (2010). Increased endothelial exocytosis and generation of endothelin- 1 contributes to constriction of aged arteries. Circ. Res. 107, 242-251. 
Goglia, L., Tosi, V., Sanchez, A. M., Flamini, M. I., Fu, X. D., Zullino, S., Genazzani, A. R., and Simoncini, T. (2010). Endothelial regulation of eNOS, PAI-1 and t-PA by testosterone and dihydrotestosterone in vitro and in vivo. Mol. Hum. Reprod. 16, 761-769.

Golden, K. L., Marsh, J. D., and Jiang, Y. (2002). Castration reduces mRNA levels for calcium regulatory proteins in rat heart. Endocrine 19, 339-344.

Gomez-Santos, C., Larque, E., Granero, E., Hernandez-Morante, J. J., and Garaulet, M. (2011). Dehydroepiandrosterone-sulphate replacement improves the human plasma fatty acid profile in plasma of obese women. Steroids 76, 1425-1432.

Hak, A. E., Witteman, J. C., de Jong, F. H., Geerlings, M. I., Hofman, A., and Pols, H. A. (2002). Low levels of endogenous androgens increase the risk of atherosclerosis in elderly men: the Rotterdam study. J. Clin. Endocrinol. Metab. 87, 3632-3639.

Harman, S. M., Metter, E. J., Tobin, J. D., Pearson, J., and Blackman, M. R. (2001). Longitudinal effects of aging on serum total and free testosterone levels in healthy men. Baltimore Longitudinal Study of Aging. J. Clin. Endocrinol. Metab. 86, 724-731.

Hwang, T. I., Liao, T. L., Lin, J. F., Lin, Y. C., Lee, S. Y., Lai, Y. C., and Kao, S. H. (2011). Low-dose testosterone treatment decreases oxidative damage in TM3 Leydig cells. Asian J. Androl. 13, 432-437.

Hyde, Z., Norman, P. E., Flicker, L., Hankey, G. J., Almeida, O. P., McCaul, K. A., Chubb, S. A., and Yeap, B. B. (2012). Low free testosterone predicts mortality from cardiovascular disease but not other causes: the health in men study. J. Clin. Endocrinol. Metab. 97, 179-189.

Ji, H., Menini, S., Mok, K., Zheng, W., Pesce, C., Kim, J., Mulroney, S., and Sandberg, K. (2005). Gonadal steroid regulation of renal injury in renal wrap hypertension. Am. J. Physiol. Renal Physiol. 288, F513F520.

Jockenhovel, F. (2004). Testosterone therapy - what, when and to whom? Aging Male 7, 319-324.

Jones, T. H., Arver, S., Behre, H. M., Buvat, J., Meuleman, E., Moncada, I., Morales, A. M., Volterrani, M., Yellowlees, A., Howell, J. D., and Channer, K. S. (2011). Testosterone replacement in hypogonadal men with type 2 diabetes and/or metabolic syndrome (the TIMES2 study). Diabetes Care 34, 828-837.
Kapoor, D., Aldred, H., Clark, S., Channer, K. S., and Jones, T. H. (2007). Clinical and biochemical assessment of hypogonadism in men with type 2 diabetes: correlations with bioavailable testosterone and visceral adiposity. Diabetes Care 30, 911-917.

Kimura, N., Mizokami, A., Oonuma, T., Sasano, H., and Nagura, H. (1993). Immunocytochemical localization of androgen receptor with polyclonal antibody in paraffinembedded human tissues. J. Histochem. Cytochem. 41, 671-678.

Laaksonen, D. E., Niskanen, L., Punnonen, K., Nyyssonen, K., Tuomainen, T. P., Valkonen, V. P., Salonen, R., and Salonen, J. T. (2004). Testosterone and sex hormonebinding globulin predict the metabolic syndrome and diabetes in middle-aged men. Diabetes Care 27, 1036-1041.

Lazarou, S., and Morgentaler, A. (2005). Hypogonadism in the man with erectile dysfunction: what to look for and when to treat. Curr. Urol. Rep. 6, 476-481.

Lerner, D. J., and Kannel, W. B. (1986). Patterns of coronary heart disease morbidity and mortality in the sexes: a 26-year follow-up of the Framingham population. Am. Heart J. 111, 383-390.

Marijic, J., Li, Q., Song, M., Nishimaru, K., Stefani, E., and Toro, L. (2001). Decreased expression of voltageand $\mathrm{Ca}(2+)$-activated $\mathrm{K}(+)$ channels in coronary smooth muscle during aging. Circ. Res. 88, 210-216.

McConnell, J. D., Wilson, J. D., George, F. W., Geller, J., Pappas, F., and Stoner, E. (1992). Finasteride, an inhibitor of 5 alpha-reductase, suppresses prostatic dihydrotestosterone in men with benign prostatic hyperplasia. J. Clin. Endocrinol. Metab. 74, 505-508.

Meinhardt, U., and Mullis, P. E. (2002). The essential role of the aromatase/p450arom. Semin. Reprod. Med. 20, 277-284.

Miller, V. M., Kaplan, J. R., Schork, N. J., Ouyang, P., Berga, S. L., Wenger, N. K., Shaw, L. J., Webb, R. C., Mallampalli, M., Steiner, M., Taylor, D. A., Bairey Merz, C. N., and Reckelhoff, J. F. (2011). Strategies and methods to study sex differences in cardiovascular structure and function: a guide for basic scientists. Biol. Sex Differ. 2, 14.

Miller, V. M., and Mulvagh, S. L. (2007). Sex steroids and endothelial function: translating basic science to clinical practice. Trends Pharmacol. Sci. 28, 263-270.
Miller, V. M., Tindall, D. J., and Liu, P. Y. (2004). Of mice, men, and hormones. Arterioscler. Thromb. Vasc. Biol. 24, 995-997.

Mombouli, J. V., and Vanhoutte, P. M. (1999). Endothelial dysfunction: from physiology to therapy. J. Mol. Cell. Cardiol. 31, 61-74.

Mooradian, A. D., Morley, J. E., and Korenman, S. G. (1987). Biological actions of androgens. Endocr. Rev. 8 $1-28$.

Morgunov, L., Denisova, I. A., Rozhkova, T. I., Stakhovskaia, L. V., and Skvortsova, V. I. (2011). Androgenic deficit and its treatment in stroke male patients with diabetes mellitus type II. Zh. Nevrol. Psikhiatr. Im. S. S. Korsakova. 111(8 Pt 2), 21-24.

Murphy, J. G., and Khalil, R. A. (1999). Decreased $[\mathrm{Ca}(2+)](\mathrm{i})$ during inhibition of coronary smooth muscle contraction by 17beta-estradiol, progesterone, and testosterone. $J$. Pharmacol. Exp. Ther. 291, 44-52.

Negro-Vilar, A. (1999). Selective androgen receptor modulators (SARMs): a novel approach to androgen therapy for the new millennium. J. Clin. Endocrinol. Metab. 84, 3459-3462.

Nettleship, J. E., Jones, R. D., Channer, K. S., and Jones, T. H. (2009). Testosterone and coronary artery disease. Front. Horm. Res. 37, 91-107.

Nettleship, J. E., Jones, T. H., Channer, K. S., and Jones, R. D. (2007). Physiological testosterone replacement therapy attenuates fatty streak formation and improves high-density lipoprotein cholesterol in the Tfm mouse: an effect that is independent of the classic androgen receptor. Circulation 116, 2427-2434.

Nguyen, C. T., Aaronson, A., Morrissey, R. P., Agarwal, M., Willix, R. D., and Schwarz, E. R. (2011). Myths and truths of growth hormone and testosterone therapy in heart failure. Expert Rev. Cardiovasc. Ther. 9 , 711-720.

O'Connell, M. D., Roberts, S. A. Srinivas-Shankar, U., Tajar, A., Connolly, M. J., Adams, J. E., Oldham, J. A., and $\mathrm{Wu}$, F. C. (2011). Do the effects of testosterone on muscle strength, physical function, body composition, and quality of life persist six months after treatment in intermediate-frail and frail elderly men? J. Clin. Endocrinol. Metab. 96 454-458.

Pike, C. J., Carroll, J. C., Rosario, E. R., and Barron, A. M. (2009). Protective actions of sex steroid hormones in Alzheimer's disease. Front. Neuroendocrinol. 30, 239-258.
Pizzi, O., Brandão, A. A., Magalhães, M. E. C., Pozzan, R., and Brandão, A. P. (2006). Pulse wave velocity. Braz. J. Hypertens. 13, 4.

Quan, A., Chakravarty, S., Chen, J. K., Chen, J. C., Loleh, S., Saini, N., Harris, R. C., Capdevila, J., and Quigley, R. (2004). Androgens augment proximal tubule transport. Am. J. Physiol. Renal Physiol. 287, F452-F459.

Quinkler, M., Bumke-Vogt, C., Meyer, B., Bahr, V., Oelkers, W., and Diederich, S. (2003). The human kidney is a progesterone-metabolizing and androgen-producing organ. J. Clin. Endocrinol. Metab. 88, 2803-2809.

Randall, V. A. (1994). Role of 5 alphareductase in health and disease. Baillieres Clin. Endocrinol. Metab. 8, 405-431.

Reckelhoff, J. F. (2005). Sex steroids, cardiovascular disease, and hypertension: unanswered questions and some speculations. Hypertension 45, 170-174.

Reckelhoff, J. F., and Romero, J. C. (2003). Role of oxidative stress in angiotensin-induced hypertension. Am. J. Physiol. Regul. Integr. Comp. Physiol. 284, R893-R912.

Reckelhoff, J. F., Yanes, L. L., Iliescu, R., Fortepiani, L. A., and Granger, J. P. (2005). Testosterone supplementation in aging men and women: possible impact on cardiovascular-renal disease. Am. J. Physiol. Renal Physiol. 289, F941-F948.

Ripple, M. O., Hagopian, K., Oberley, T. D., Schatten, H., and Weindruch R. (1999). Androgen-induced oxidative stress in human LNCaP prostate cancer cells is associated with multiple mitochondrial modifications. Antioxid. Redox Signal. 1, 71-81.

Romanelli, F., Sansone, A., and Lenzi, A. (2010). Erectile dysfunction in aging male. Acta Biomed. 81(Suppl. 1), 89-94.

Ruige, J. B., Mahmoud, A. M., De Bacquer, D., and Kaufman, J. M. (2011). Endogenous testosterone and cardiovascular disease in healthy men: a meta-analysis. Heart 97, 870-875.

Sa, E. Q., Sa, F. C., Guedes, A. D., and Verreschi, I. T. (2009). Serum testosterone and cardiovascular disease in men. Arq. Bras. Endocrinol. Metabol. 53, 915-922.

Saad, F., Gooren, L. J., Haider, A., and Yassin, A. (2008). A dose-response study of testosterone on sexual dysfunction and features of the metabolic syndrome using testosterone gel and parenteral testosterone undecanoate. J. Androl. 29, 102-105. 
Sadanaga, T., Ohya, Y., Ohtsubo, T., Goto, K., Fujii, K., and Abe, I. (2002). Decreased 4-aminopyridine sensitive $\mathrm{K}+$ currents in endothelial cells from hypertensive rats. Hypertens. Res. 25, 589-596.

Sader, M. A., McCredie, R. J., Griffiths, K. A., Wishart, S. M., Handelsman, D. J., and Celermajer, D. S. (2001). Oestradiol improves arterial endothelial function in healthy men receiving testosterone. Clin. Endocrinol. (Oxf.) 54, 175-181.

Seftel, A. D., Mack, R. J., Secrest, A. R., and Smith, T. M. (2004). Restorative increases in serum testosterone levels are significantly correlated to improvements in sexual functioning. J. Androl. 25, 963-972.

Shabsigh, R., Rajfer, J., Aversa, A., Traish, A. M., Yassin, A., Kalinchenko, S. Y., and Buvat, J. (2006). The evolving role of testosterone in the treatment of erectile dysfunction. Int. J. Clin. Pract. 60, 1087-1092.

Shih, H., Lee, B., Lee, R. J., and Boyle, A. J. (2011). The aging heart and postinfarction left ventricular remodeling. J. Am. Coll. Cardiol. 57, 9-17.

Simerly, R. B., Chang, C., Muramatsu, M., and Swanson, L. W. (1990). Distribution of androgen and estrogen receptor mRNA-containing cells in the rat brain: an in situ hybridization study. J. Comp. Neurol. 294, 76-95.

Song, D., Arikawa, E., Galipeau, D., Battell, M., and McNeill, J. H. (2004). Androgens are necessary for the development of fructoseinduced hypertension. Hypertension 43, 667-672.

Thigpen, A. E., Silver, R. I., Guileyardo, J. M., Casey, M. L., McConnell, J. D., and Russell, D. W. (1993). Tissue distribution and ontogeny of steroid 5 alpha-reductase isozyme expression. J. Clin. Invest. 92, 903-910.

Thijssen, D. H., Rongen, G. A., van Dijk, A., Smits, P., and Hopman, M. T. (2007). Enhanced endothelin-1mediated leg vascular tone in healthy older subjects. J. Appl. Physiol. 103, 852-857.

Titus, M. A., Schell, M. J., Lih, F. B., Tomer, K. B., and Mohler, J. L. (2005). Testosterone and dihydrotestosterone tissue levels in recurrent prostate cancer. Clin. Cancer Res. 11, 4653-4657.

Tokunaga, O., Fan, J., Watanabe, T., Kobayashi, M., Kumazaki, T., and Mitsui, Y. (1992). Endothelin. Immunohistologic localization in aorta and biosynthesis by cultured human aortic endothelial cells. Lab. Invest. 67, 210-217.

Tostes, R. C., Fortes, Z. B., Callera, G. E., Montezano, A. C., Touyz, R. M., Webb, R. C., and Carvalho, M. H. (2008). Endothelin, sex and hypertension. Clin. Sci. 114, 85-97.

Toufexis, D. J., and Wilson, M. E. (2012). Dihydrotestosterone differentially modulates the cortisol response of the hypothalamic-pituitary-adrenal axis in male and female rhesus macaques, and restores circadian secretion of cortisol in females. Brain Res. 1429, 43-51.

Tuck, S. P., and Francis, R. M. (2009). Testosterone, bone and osteoporosis. Front. Horm. Res. 37, 123-132.

Ungvari, Z., Kaley, G., de Cabo, R., Sonntag, W. E., and Csiszar, A. (2010). Mechanisms of vascular aging: new perspectives. J. Gerontol. A Biol. Sci. Med. Sci. 65, 1028-1041.
Van Guilder, G. P., Westby, C. M. Greiner, J. J., Stauffer, B. L., and DeSouza, C. A. (2007). Endothelin-1 vasoconstrictor tone increases with age in healthy men but can be reduced by regular aerobic exercise. Hypertension 50, 403-409.

Vanhoutte, P. M., Shimokawa, H., Tang, E. H., and Feletou, M. (2009). Endothelial dysfunction and vascular disease. Acta Physiol. (Oxf.) 196, 193-222.

Wu, F. C., and von Eckardstein, A. (2003). Androgens and coronary artery disease. Endocr. Rev. 24, 183-217.

Xu, Q., Wells, C. C., Garman, J. H., Asico, L., Escano, C. S., and Maric, C. (2008). Imbalance in sex hormone levels exacerbates diabetic renal disease. Hypertension 51, 1218-1224.

Yang, X. P., and Reckelhoff, J. F. (2011). Estrogen, hormonal replacement therapy and cardiovascular disease. Curr. Opin. Nephrol. Hypertens. 20, 133-138.

Yang, Y. M., Huang, A., Kaley, G., and Sun, D. (2009). eNOS uncoupling and endothelial dysfunction in aged vessels. Am. J. Physiol. Heart Circ Physiol. 297, H1829-H1836.

Yaron, M., Greenman, Y., Rosenfeld, J. B., Izkhakov, E., Limor, R., Osher, E., Shenkerman, G., Tordjman, K., and Stern, N. (2009). Effect of testosterone replacement therapy on arterial stiffness in older hypogonadal men. Eur. J. Endocrinol. 160, 839-846.

Yildiz, O. (2007). Vascular smooth muscle and endothelial functions in aging. Ann. N. Y. Acad. Sci. 1100, 353-360.

Yildiz, O., Seyrek, M., Gul, H., Un, I. Yildirim, V., Ozal, E., Uzun, M., and
Bolu, E. (2005). Testosterone relaxes human internal mammary artery in vitro. J. Cardiovasc. Pharmacol. 45, 580-585.

Yue, P., Chatterjee, K., Beale, C., PooleWilson, P. A., and Collins, P. (1995). Testosterone relaxes rabbit coronary arteries and aorta. Circulation 91, 1154-1160.

Zhou, P., Fu, L., Pan, Z., Ma, D., Zhang, Y., Qu, F., Guo, L., Cao, J., Gao, Q., and Han, Y. (2008). Testosterone deprivation by castration impairs expression of voltagedependent potassium channels in rat aorta. Eur. J. Pharmacol. 593, 87-91.

Conflict of Interest Statement: The authors declare that the research was conducted in the absence of any commercial or financial relationships that could be construed as a potential conflict of interest.

Received: 25 January 2012; accepted: 25 March 2012; published online: 10 April 2012.

Citation: Lopes RAM, Neves KB Carneiro FS and Tostes RC (2012) Testosterone and vascular function in aging. Front. Physio. 3:89. doi: 10.3389/fphys.2012.00089

This article was submitted to Frontiers in Vascular Physiology, a specialty of Frontiers in Physiology.

Copyright () 2012 Lopes, Neves, Carneiro and Tostes. This is an open-access article distributed under the terms of the Creative Commons Attribution Non Commercial License, which permits noncommercial use, distribution, and reproduction in other forums, provided the original authors and source are credited. 